\title{
Halogen-Free Flame-Retardant Thermoplastic Polyurethanes
}

\author{
D. R. HALL, M. M. HIRSCHLER, and C. M. YAVORNITZKY \\ BFGoodrich Chemical Company \\ Technical Center, P.O. Box 122 \\ Avon Lake, Ohio 44012, USA
}

\section{ABSTRACT}

Studies have been made of the flammability of a thermoplastic polyurethane incorporating a halogen-free additive flame-retardant system. clear-cut evidence of synergism has been shown for the interaction between the additives. Thermoanalytical studies have shown that the crucial reaction for synergism is the enhanced production of ammonia and that this only occurs when the two phosphorus- and nitrogen-containing additives are present. The overall pattern of thermal decomposition of the polymer-additives system shows slow but steady thermal activity over a wide range of temperatures; this is indicative of synergism in a condensed-phase mechanism. The most important flame-retardant effect is thus the formation of a charry intumescent foam, but there is also some physical and chemical gas-phase activity. The resulting thermoplastic polyurethanes can be produced with an LOI of over 40 and a UL94 ranking of yo, in the total absence of halogen.

\section{TNTRODUCTION}

Thermoplastic polyurethanes are tough and versatile materials, with a good combination of processing and performance characteristics. Their levels of production have grown very rapidly in recent years, in particular in the U.S. They have risen from 13000 tons in $1975^{1}$ to 38000 tons in 1984.2 A typical application of these resins is in tubing for the enclosure of wires on board ships which are being reconditioned. It is essential for such a use that the polymers should have been flame-retarded, to help protect against ignition due to sparks and short-circuits. This flame retardance has traditionally been achieved by employing antimony oxide-halogen systems. It is of interest, however, to investigate other additives because some concern has been voiced about the emission of potentially corrosive hydrogen halides in some electrical applications.

The combustion of any organic polymer can be represented by a series of three interdependent and interrelated stages: 3,4 (a) thermal decomposition of the base polymer to yield flammable gaseous products; (b) flaming combustion of these products leading to the generation of heat and (c) transport of this heat back to the polymer surface to restart the cycle. Flame retardance can thus be achieved by interacting with one or more of these stages. The mechanism of action of antimony/halogen flame retardants is a mixture of effects on the first two stages, viz. the additives change the decomposition pattern of the resin (inter alia by slowing down the rate of breakdown), 3,7 and they inhibit the flame propagation reactions by the scavenging action of antimony and halogen species in the gas phase. $3,4,8,9$ such systems are, however, sometimes associated with 
dripping products and with large emissions of smoke particles.

Intumescent systems act by creating a charry foam, blown up by the action of evolved non-flammable gaseous products, which insulates the bulk of the polymer from the effect of further heat. $3,10-12$ ' Such an additive system is thus potentially more complete than the one described previously because it can act by interfering with all three stages of the combustion process. A typical intumescent system contains a "carbonific" (which is the source of the carbon producing the charry residue), a "spumific" (which generates the non-flammable gases) and a "catalyst" (which promotes decomposition of the carbonific compound, typically by forming an inorganic compound at temperatures between 475 and $525 \mathrm{~K}$ ). In many cases, more than one of these functions is performed by the same compound.

The present paper presents an investigation to search for a flame-retarded thermoplastic polyurethane (TPU) which is halogen-free. The additive systems used are phosphorus-based and contain up to three individual compounds in combinations chosen so as to achieve synergistic interactions leading to better overall performance than would have been possible with any individual additive. Ammonium polyphosphate is known to be an additive which can induce the formation of an intumescent char in thermoplastic materials;13-15 it was therefore thought possible that it would be a much more effective flame retardant in the presence of a synergistic co-additive.

It has recently been shown that thermoanalytical measurements are a very useful source of data to allow interpretations to be made of the mechanism of flame-retardant action. 6,7 Thermal analysis was thus the main tool used to obtain non-flame data for analysis of the results of the present work.

\section{EXPERIMENTAL}

Materials

The thermoplastic polyurethane (TPU) used is a Shore $85 \mathrm{~A}$ hardness, polyether urethane from $1000 \mathrm{Mw}$ polytetramethylene ether glycol, 4-4 diphenylmethane dilisocyanate and 1,4-butane diol (an ESTANE ${ }^{\odot}$ resin); all three flame-retardant additives used, viz. bis melaminium pentate (Borg-Warner) ${ }^{16}$ (MAP), ammonium polyphosphate (APP) and isopropylphenyl diphenyl phosphate (Kronitex 100, FMC Corp.) (KX) are phosphorus-based.

\section{Procedure}

Flame-retardant additive densities were determined by air displacement pycnometry for volumetric evaluations. Liquid additive $K X$ was presorbed into the TPU at $293 \mathrm{~K}$. The remaining additives, including lubricant and pigment, were incorporated by melt-mixing at $448 \mathrm{~K}$ in a $54 \mathrm{~cm}^{3}$ batch-size Brabender internal mixer.

\section{Flammability}

The flammability of the system was determined by measuring the limiting oxygen index (LOI) on equipment designed to meet ASTM D2863 flammability test requirements and the UL.94 vertical flammability ranking on similarly appropriate equipment. The standard UL94 test classifies samples into $V 0, V 1$ or $V 2$ categories and it was used in order to investigate the flame spread time and the dripping characteristics of the sample (at $3 \mathrm{~mm}$ thickness) following piloted ignition.

\section{Thermal Analysis}

A DuPont 1090 thermogravimetric analyzer was used for all experiments; a 
heating rate of $10 \mathrm{deg} \mathrm{min}^{-1}$ and an atmosphere of nitrogen (at a flow rate of $180 \mathrm{~cm}^{3} \mathrm{~min}^{-1}$ ) were used throughout. Char yields were compared with those obtained from a BFGoodrich proprietary smoke/char test, 17 which measures smoke production (photometrically) and char residue following the rapid (30 s) combustion of small samples ignited by a pencil tip propane flame.

\section{RESULTS AND DISCUSSION}

The pure thermoplastic polyurethane decomposes thermally by a mechanism involving four stages, the temperature ranges of which were $543-635,635-656,656-$ 756 and $756-832 \mathrm{~K}$ (Table 1 ). The most important aspects of this decomposition are: a) the fact that the first two stages are very fast, and account for over $60 \%$ of the total weight and b) the fact that the final weight loss stage, which corresponds to char pyrolysis is, on the other hand, quite slow and accounts for ca. 15 wt\%. The TPU starts decomposing substantially only at a very high temperature since the temperature at which $1.0 \mathrm{wt} \%$ has been lost $6,7^{\circ}\left(\mathrm{T}_{1 \%}\right)$ is $543 \mathrm{~K}$, which suggests that depolycondensation has already occurred before decomposition started, but that it has led to involatile fragments (by comparison with other polyurethanes 18,19 ).

The thermal decomposition of MAP is very complex: it consists of seven stages (Table 1). The two most important stages are the production of ammonia (corresponding to ca. $23 \mathrm{wt} \%$ ) and the char pyrolysis (corresponding to some $40 \%$ of the weight of the additive). The ammonia stage (maximum rate at $590 \mathrm{~K}$ ) is the fastest breakdown in an otherwise rather slow decomposition covering a wide temperature range (335-1115 K) (Figure 1). APP breaks down in three stages (Table 1) corresponding, successively, to the slow elimination of ammonia (at virtually the same temperature as MAP eliminates ammonia; maximum rate at $581 \mathrm{~K}$ ), to the slow elimination of water (these two stages accounting together for ca. $25 \%$ of the initial weight) and to a very fast breakdown of the remaining cross-linked phosphorus-containing residue (ultraphosphate), occurring much later. This is similar to what has been shown by other authors. 14 The thermal decomposition of $K X$ is very simple: it volatilizes in a single stage (and probably unchanged) at $543 \mathrm{~K}$.

Figure 2 shows the thermal decomposition pattern of the pure TPU and of systems containing the resin with 20 vol\% of each additive, individually. The object of this is to try to understand the individual effects of the additives so as to be able to interpret the effects of their combinations. It has been shown that synergism in flame retardance is almost invariably accompanied by clear changes in the thermogravimetric pattern. $6,7,20-24$ It is perhaps somewhat surprising that the effects of MAP and APP on the resin are very similar: both decrease the thermal stability of the system (although APP is significantly more effective in doing this, as shown by $T_{1 \%}$, in Table 1) while they promote the first decomposition stage of the resin at the expense of the second one and, particularly, of the third one, which virtually disappears. Furthermore, Table 1 shows that char pyrolysis occurs at a much higher temperature in the presence of either of these additives (temperature range $880-1100 \mathrm{~K}$, rather than $750-930 \mathrm{~K}$ ), while there does not seem to be very much additional char formed. The $N$-free additive, $K X$, has very little effect: it simply volatilizes just before polymer breakdown (maximum rate of this stage at ca. $550 \mathrm{~K}$ ). Furthermore, the char pyrolysis stage occurs at the same temperature range than in the pure TPU as distinct from the cases of the other two additives. One effect of $\mathrm{KX}$ is that it brings together the first two weight loss stages of the TPU.

Figure 3 shows the comparison, for a large number of systems, between the char (+ residue) remaining after the smoke/char test 17 (in the ordinate) and the char (+ residue) formed under thermogravimetric (TGA) conditions (in the abscissa); the base resin is the same TPU in all cases. It is clear that additives can 
TABLE 1. Thermal analyses of polymer, additives and polymer-single additive systems

\begin{tabular}{|c|c|c|c|c|c|c|c|}
\hline $\begin{array}{l}\text { Initial Weight }(\mathrm{mg}) \\
\text { Total Weight Lost }(\%) \\
T_{1 \%}(k) \\
T_{1 \%}(k)\end{array}$ & $\begin{array}{l}\text { TPU } \\
\text { ESTANE } \\
18.28 \\
99.1 \\
441 \\
543\end{array}$ & $\begin{array}{l}\text { TPU }+ \\
20 \% \text { MAP } \\
200.21 \\
98.9 \\
378 \\
445\end{array}$ & $\begin{array}{l}\text { TPU + } \\
20 \% \text { APP } \\
24.86 \\
99.3 \\
459 \\
508\end{array}$ & $\begin{array}{l}\text { TPU t } \\
20 \% \mathrm{KX} \\
\frac{15.88}{15.88} \\
99.4 \\
456 \\
488\end{array}$ & $\begin{array}{l}\text { MAP } \\
9.80 \\
97.5 \\
336 \\
353\end{array}$ & $\begin{array}{l}\text { APP } \\
9.55 \\
95.1 \\
341 \\
496\end{array}$ & $\begin{array}{l}k x \\
13.86 \\
99.4 \\
441 \\
465\end{array}$ \\
\hline 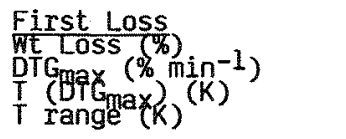 & $\begin{array}{l}1.5 \\
0.55 \\
543 \\
441-543\end{array}$ & $\begin{array}{l}1.5 \\
0.30 \\
436 \\
378-486\end{array}$ & $\begin{array}{l}1.5 \\
0: 50 \\
507 \\
459-517\end{array}$ & $\begin{array}{l}5.0 \\
1.30 \\
413 \\
456-575\end{array}$ & $\begin{array}{l}4.0 \\
1.30 \\
366 \\
336-382\end{array}$ & $\begin{array}{l}9.5 \\
1.60 \\
581 \\
341-603\end{array}$ & $\begin{array}{l}99.4 \\
27.30 \\
546 \\
441-565\end{array}$ \\
\hline 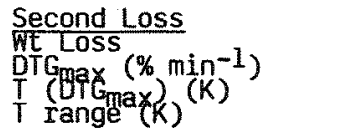 & $\begin{array}{l}47.0 \\
10 ; 50 \\
612 \\
543-635\end{array}$ & $\begin{array}{l}37.5 \\
11: 80 \\
578 \\
486-597\end{array}$ & $\begin{array}{l}30.5 \\
9.90 \\
555 \\
517-577\end{array}$ & $\begin{array}{l}\frac{17.5}{4.00} \\
554 \\
525-576\end{array}$ & $\begin{array}{l}2.5 \\
0.90 \\
408 \\
382-439\end{array}$ & $\begin{array}{l}8.5 \\
0.90 \\
617 \\
603-693\end{array}$ & \\
\hline 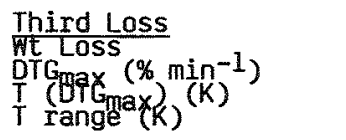 & $\begin{array}{l}13.5 \\
9.20 \\
645 \\
635-656\end{array}$ & $\begin{array}{l}21.4 \\
6.70 \\
612 \\
597-637\end{array}$ & $\begin{array}{l}28.0 \\
5.40 \\
600 \\
577-650\end{array}$ & $\begin{array}{l}41.0 \\
8.80 \\
612 \\
576-651\end{array}$ & $\begin{array}{l}6.0 \\
1.50 \\
509 \\
439-533\end{array}$ & $\begin{array}{l}77.1 \\
13.2 \\
836 \\
693-973\end{array}$ & \\
\hline $\begin{array}{l}\text { Fourth Loss } \\
\text { WT Loss (m) } \\
\text { DTG gax (min-1) } \\
\text { T (GTG max) (K) } \\
\text { T range }(K)\end{array}$ & $\begin{array}{l}21.5 \\
5.00 \\
673 \\
656-756\end{array}$ & $\begin{array}{l}15.5 \\
3.40 \\
644 \\
637-766\end{array}$ & $\begin{array}{l}6.0 \\
0.80 \\
674 \\
650-761\end{array}$ & $\begin{array}{l}21.0 \\
4.20 \\
681 \\
651-761\end{array}$ & $\begin{array}{l}23.0 \\
4.90 \\
590 \\
533-637\end{array}$ & & \\
\hline 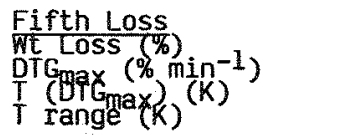 & $\begin{array}{l}15.6 \\
1.50 \\
834 \\
756-932\end{array}$ & $\begin{array}{l}6.0 \\
0.80 \\
781 \\
766-880\end{array}$ & $\begin{array}{l}9.8 \\
1.30 \\
852 \\
761-885\end{array}$ & $\begin{array}{l}14.9 \\
1.70 \\
830 \\
761-970\end{array}$ & $\begin{array}{l}14.5 \\
1.90 \\
693 \\
637-728\end{array}$ & & \\
\hline 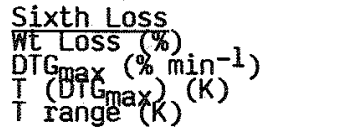 & & $\begin{array}{l}17.0 \\
1.30 \\
1005 \\
880-1100\end{array}$ & $\begin{array}{l}23.5 \\
2.20 \\
956 \\
885-1115\end{array}$ & & $\begin{array}{l}8.5 \\
2.10 \\
756 \\
728-787\end{array}$ & & \\
\hline 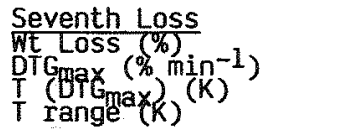 & & & & & $\begin{array}{l}39.0 \\
1.90 \\
1014 \\
787-1135\end{array}$ & & \\
\hline
\end{tabular}




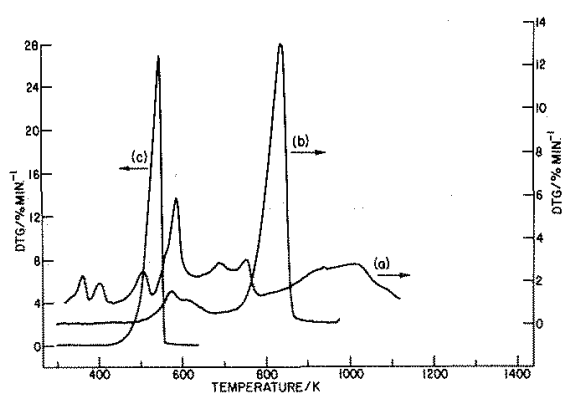

FIGURE 1. Differential thermogravimetric analysis of the additives. (a) MAP; (b) APP; (c) KX. A zero value for the ordinate of curve (a) is at a DTG of $1 \% \min ^{-1}$.

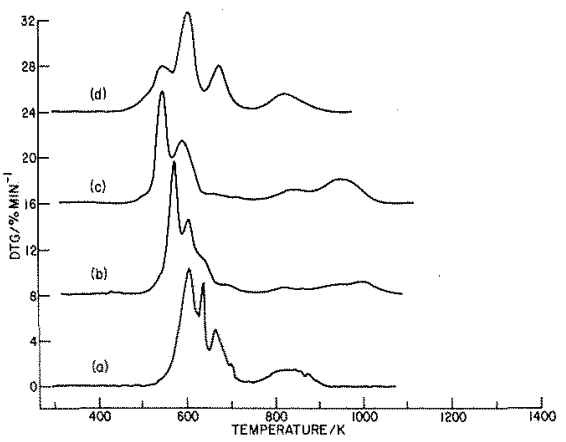

FIGURE 2. Differential thermogravimetric analysis of the polymeric substrate in the absence and presence of $20 \mathrm{vol} \%$ of each additive individually. (a) TPU; (b) TPU + 20 vol\% MAP; (c) TPU + 20 vol \% APP; (d) TPU + 20 vol\% $\mathrm{kX}$. Zero values for the ordinates of successive curves are at $6 \%$ min $^{-1}$ intervals.

fall into two major categories in this respect: (a) those which form much more char on burning than on being heated slowly (roughly twice as much, on average) and (b) those which produce at least as much (or more) char under thermoanalytical conditions than on burning. The dashed line (of slope 1.0) separates the two groups of additives. This result is relevant to the phenomenon of intumescence. It has been shown that it is important to match the temperatures of gas evolution

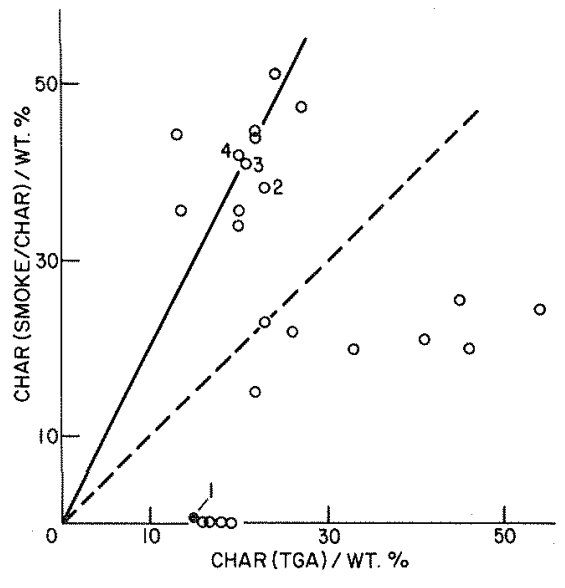

FIGURE 3. Relationship between thermoanalytical and combustion char. : pure polymer; : polymer containing additives; : slope for intumescent additives; - slope of 1.0. (1) TU +20 vol $\% \mathrm{KX} ;$ (2) TPU +20 vol\% APP; (3) TPU + 30 vol\% APP; (4) TPU + 20 vol\% MAP. 
to the physico-chemical properties of the degrading polymer-additive mixture at the same temperature for efficient intumescent flame retardance.10,14, 25 Fur-

thermore, it is likely that, when heating is slow and a situation approaching equilibrium is attained at every temperature, the charry layer being formed is more likely to be gradually destroyed than in short experiments. It is, thus, probable that the group of additives in a) (including both MAP and APP) would all tend to cause intumescence while the additives in b) (including $K X$ ) would have some other flame-retardant effects (or none). For both MAP and APP (as for most additives in group a)), the smoke production of the sample is much lower than that of the pure substrate: integrated smoke values are 5-10 times lower.

Returning now to the flammability of the TPU resin, each of the additives individually can induce, at a sufficiently high loading, the attainment of a UL.94 vo rating, but this is brought about by different mechanisms. The effect of $K X$ is probably concentrated in the free-radical scavenging action of phosphorus-containing species, which have been volatilized. This gas-phase mechanism is a well established one for thermoplastic polymers in the presence of organic phosphoruscontaining flame retardants. 3 Thermal analysis results and the lack of any major effect on char formation or smoke production (by the smoke/char test) suggest thus that $K X$ does not have a condensed-phase mechanism but may be an aid in a multi-component additive system, by its gas-phase activity.

APP, a potential spumific agent for intumescence, increases char production and decreases smoke generation, but has a very low efficiency as a flame retardant Its monomer, ammonium phosphate, is a typical intumescent catalyst. 3 Its efficient interaction (in the thermoanalyzer) with the substrate suggests that the polymeric form might also be a potential catalyst for intumescence. Furthermore, at 30 vol\% additive loading, the TPU + APP system shows a breakdown stage (between the two first polymer stages) where volatilization of ammonia occurs and which accounts for up to $10 \mathrm{wt} \%$ of the entire system. This same system also shows further increases in char production from the resin (from 15 wt\% to 35 wt\% of resin), presumably because of the formation of the intumescent charry layer across the surface of the condensed phase. This is of low efficiency, unfortunately, because it follows a rather fast first weight loss stage for the resin.

MAP is a potential carbonific; it also decreases both the flaming characteristics of TPU and the smoke generated from it, while increasing char production. Furthermore, it is capable of releasing inert gases (ammonia in this case) and it contains a structural part (melamine phosphate) which is a potential intumescent catalyst. 3

Consequently, over 50 systems were tried in which various combinations of TPU with MAP and APP were investigated for flammability, both in the absence and in the presence of $\mathrm{kX}$. The LOI values determined for the systems were fitted by a polynomial function of a linear transformation of the composition coordinates and represented in two triangular diagrams (Figure 4, in the absence of $K X$, and Figure 5 , in the presence of $K X) .9,26$ Coefficients of the polynomials were calculated by least-squares regression analysis and the quality of the fit assessed by the value of the root mean square differences between the calculated and observed LOI values $(\sigma)$, by the multiple regression correlation coefficients (RCC), by examination of the individual differences between calculated and observed LOI values and by comparison with experimental trends. The vertices of the triangles shown correspond to (A) $100 \%$ TPU; (B) 62.92 vol\% TPU; 37.08 vol\% APP; (C) 62.92 vol\% TPU; 37.08 vol\% MAP. In both cases there is very clear evidence of synergism with LOI values of well over 40 (as compared with values of 22.1 for the pure resin and of well under 30 for maximum loading of each individual additive). The mathematical fit of the data is more than adequate so that the triangular diagrams shown (cubic models) are good representations of the trends. It 

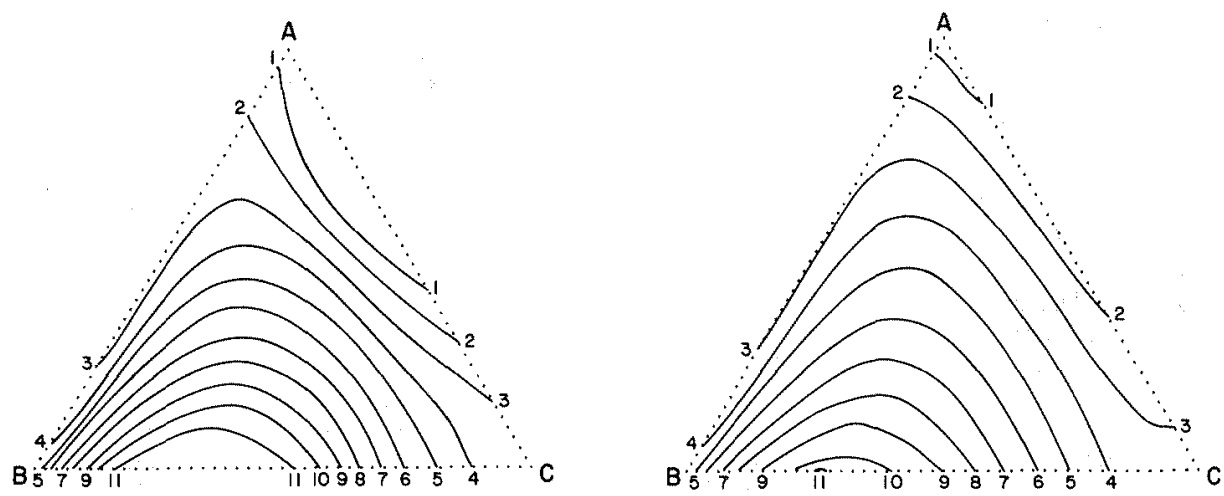

FIGURE 4. The flammability (by LOI) of

FIGURE 5. The flammability (by LOI) of the systems containing TPU, MAP and APP. the systems containing TPU, MAP, APP and $(\mathrm{RCC}=0.867)$.

KX. $\quad(\mathrm{RCC}=0.936)$.

A: $\quad(1.00 ; 0.00 ; 0.00) ; 8: \quad(0.63 ; 0.37 ; 0.0) ; C: \quad(0.63 ; 0.00 ; 0.37)$ LOI Values: $1,23.0 ; 2,25.0 ; 3,27.0 ; 4,29.0 ; 5,31.0 ; 6,33.0 ; 7,35.0 ; 8,37.0$; $9,39.0 ; 10,41.0 ; 11,43.0$.

can be calculated from these diagrams that optimum volumetric ratios of APP to MAP (i.e. those which will yield highest LoI values) lie between 1.5 and 3.0 ; furthermore the diagrams show that LOI values of well over 30 can be obtained without very high levels of additives. The third additive $(K X)$ can be effective in decreasing the flammability of the resin at relatively low total loadings, but becomes quite unnecessary, for flammability purposes, at very high loadings.

Table 2 shows that UL94 vo rankings can be obtained for loadings as low as 19 vol\% of additives but that, at higher loadings (in the presence of some $K X$ ), Vo spectra can be obtained for wider ranges of APP to MAP ratios.

TABLE 2. UL94 vertical flammability rankings

\begin{tabular}{|c|c|c|c|c|c|}
\hline & PNB/PNA & PNB/PNA & PNB/PNA & PNB/PNA & PNB/PNA \\
\hline & $1 / 0^{\mathrm{a}}$ & $3 / 1^{a}$ & $1 / 1^{a}$ & $1 / 3^{a}$ & $0 / 1^{a}$ \\
\hline 19 vol \%b & $\sqrt{ } 2$ & vo & $\sqrt{2}$ & V2 & v2 \\
\hline 23 vol \%b & $v_{2}$ & vo & vo & VI & $v_{2}$ \\
\hline 26 Vol \%b & $v_{2}$ & vo & vo & vo & v2 \\
\hline 30 vol \%b & $v_{2}$ & vo & vo & vo & v2 \\
\hline $33 \mathrm{Vol} \% \mathrm{~b}$ & vo & vo & vo & vo & v2 \\
\hline 37 vol \%b & vo & vo & yo & Vo & vi \\
\hline
\end{tabular}

a volumetric ratio of additives; $b$ Total additive level.

Figures 6 and 7 show the differential thermogravimetric pattern of a series of systems at constant total loading where the ratios of MAP to APP are gradually varied. It can be seen that there is, in both diagrams, a noticeable change: the stage corresponding to ammonia liberation (at $\mathrm{ca}, 600 \mathrm{~K}$ ) is almost negligible when either MAP or APP are missing. However, it is the dominant stage when the ratio 
of APP to MAP is 1 or higher; at such ratios it displaces the second weight loss peak for the resin to higher temperatures and slows down the corresponding rate of breakdown. Furthermore, thermal activity is continuous over the temperature range of 520-1190 $\mathrm{K}$ at a fairly constant and quite low decomposition rate with high char production. It has been shown that these are necessary characteristics for the achievement of good flame-retardant synergism. 6 Thus, the thermograms are a clear indication of the mechanism that results in the synergism: MAP interacts with APP and the liberation of ammonia is enhanced. This, in turn, since it has occurred after some initial breakdown of the polymeric structure, will form a charry intumescent foam (although this char is less noticeable in thermoanalytical than in burning experiments) which will protect the bulk of the resin from further decomposition. Finally, if heat continues to be applied, the charry layer breaks down slowly. In the meantime, the flame reactions are also slowed down by gasphase effects, both physical (due to the cooling effects of some of the ammonia which escapes from the foam and is non-flammable) and chemical (due to the phosphorus-containing species from $K X$ ). Such an increased char production will also help decrease the smoke production tendency, 27 since it is clear that the carbon needed for smoke is partly being retained in the condensed phase.

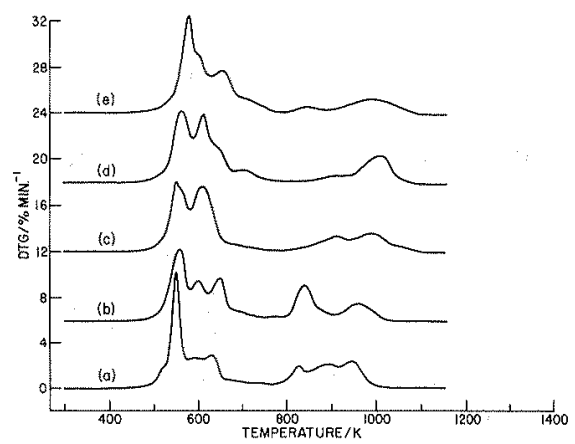

FIGURE 6. Differential thermogravimetry of the TPU in the presence of 30 vol \% of varying proportions of MAP and APP.

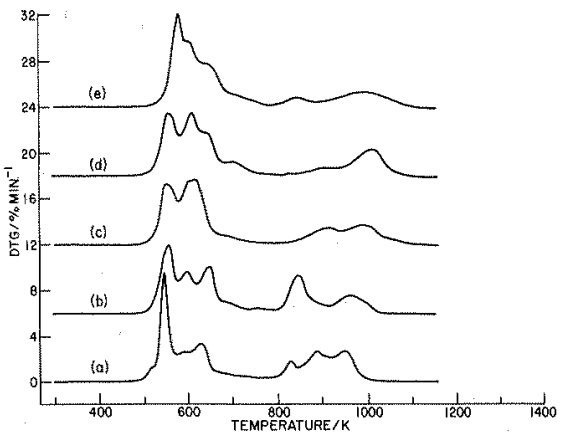

FIGURE 7. Differential thermogravimetry of the TPU in the presence of $30 \mathrm{vol} \%$ (with respect to TPU) of varying proportions of MAP and APP, and in the presence, additionally, of $\mathrm{kX}$.

(a) 30.0 vol\% APP; (b) 22.5 vol\% APP + 7.5 vol\% MAP; (c) 15.0 vol\% APP + 15.0 vol\% MAP; (d) 7.5 vol\% APP + 22.5 vol\% MAP; (e) 30.0 vol\% MAP. Zero values for the ordinates of successive curves are at $6 \% \mathrm{~min}^{-1}$ intervals.

At high loadings of MAP and APP (e.g. 30 vol\% or higher) the gas phase activity of $K X$ becomes mostly superseded and is thus scarcely noticeable. This transpires both from the thermoanalytical pattern (Figures 6 and 7) and from the flammability pattern (Figures 4 and 5).

An excellent correspondence between the findings of the thermoanalytical and flammability measurements is another example of the good extrapolatability of thermal analysis as a first-order approximation model for some of the phenomena occurring in burning polymers. This has helped to establish a model for the synergistic flame-retardant mechanism of an additive system, for a thermoplastic polyurethane, which is halogen-free and exhibits extremely low flammability and smoke under the conditions investigated. 
Caveat: The flammability test data reported here represent laboratory smallscale measurements and are not necessarily indicative of the response of the materials to a full-scale fire scenario.

\section{CONCLUSIONS}

Thermoanalytical measurements and flammability determinations have shown the synergistic flame retardant activity of an additive system for a thermoplastic polyurethane containing phosphorus and nitrogen but no halogen. The flame-retardant acts on all three stages of the combustion cycle, but its most important effect is the formation of an intumescent charry foam on the surface of the polymer. Very low flammability is achieved with LOI values of over 40 and a UL94 ranking of vo accompanied by high char and low smoke.

\section{REFERENCES}

1. Modern Plastics, 54(1), 49 (1977).

2. Modern Plastics, 62(1), 61 (1985).

3. Cullis, C. F. and Hirschler, M. M., "The Combustion of Organic Polymers," Oxford University Press, Oxford, 1981.

4. Hirschler, M. M., in "Developments in Polymer Stabjlization-5" (Ed. G. Scott), p. 107, Applied Science Publ., London, 1982.

5. Learmonth, G. S. and Thwaite, D. G., Brit. Polymer J. 2, 104 (1970).

6. Hirschler, M. M., Europ. Polymer 19, 121 (1983).

7. Cullis, C. F. and Hirschler, M. M., Polymer 24, 834 (1983).

8. Hastie, J. W., J. Res. Natl Bur. Stand. 77A, 733 (1973).

9. Antia, F. K., Baldry, P. J. and Hirschler, M. M., Europ. Polymer J. 18, 167 (1982).

10. Vandersall, H. L., J. Fire Flammability 2, 97 (1971).

11. Rheineck, A. E., J. Paint. Technol. 44 (567), 35 (1972).

12. Hindersinn, R. R. and Witschard, G., in "Flame Retardancy of Polymeric Materials - Vol. 4" (Ed. W. C. Kuryla and A. J. Papa), p. 1, Marcel Dekker Publ., New York, 1978.

13. Camino, G., Grassie, N. and McNeill, I. C., J. Polymer Sci., Polym. Chem. 16, 95 (1978).

14. Camino, G., Costa, L. and Trossarelli, L., Polymer Degrad. and Stabil. 6 , 243 (1984).

15. Camino, G. Costa, L. and Trossarelli, L. Polymer Degrad. and Stabil. Z, 25 (1984).

16. Halpern, Y., U.S. Pat. No. 4154930, May 15, 1979 (to Borg-Warner Corp.).

17. W. J. Kroenke, J. Appl. Polymer Sci. 26, 1167 (1981). 
18. Ballistreri, A., Foti, S., Maravigna, P., Montaudo, G. and Scamporrino, E., Makromol. Chem. 181, 2161 (1980).

19. Montaudo, G., Puglisi, C., Scamporrino, F. and Vitalini, D. Macromolecules 17, 1605 (1984).

20. Donaldson, J. D., Donbavand, J. and Hirschler, M. M., Europ. Polymer J. 19, 33 (1983).

21. Hirschler, M. M. and Tsika, 0., Europ. Polymer J. 19, 375 (1983).

22. Cullis, C. F., Hirschler, M. M. and Khattab, M. A. A. M., Europ. Polymer J. 20, 559 (1984).

23. Broadbent, J. R. A. and Hirschler, M. M., Europ. Polymer J. 20, 1087 (1984).

24. Hirschler, M. M. and Thevaranjan, T. R., Europ. Polymer J. 21, 371 (1985).

25. Chang, W. H., Scriven, R. L. and Ross, R. B., in "Flame-retardant polymeric materials, Vol. 1" (Ed. M. Lewin, S. M. Atlas and E. M. Pearce), p. 399, Plenum Press, New York, 1975.

26. Antia, F. K., Cullis, C. F. and Hirschler, M. M., Europ. Polymer J. 18, 95 (1982).

27. Cullis, C. F. and Hirschler, M. M., Europ. Polymer J. 20, 53 (1984). 